OPEN ACCESS

Edited by:

Dora Reglodi,

University of Pécs, Hungary

Reviewed by:

Victor May,

University of Vermont, United States

Seiji Shioda

Hoshi University, Japan Hitoshi Hashimoto,

Osaka University, Japan

${ }^{*}$ Correspondence:

Marieke R. Gilmartin

marieke.gilmartin@marquette.edu

Specialty section:

This article was submitted to Cellular Neurophysiology,

a section of the journal

Frontiers in Cellular Neuroscience

Received: 02 February 2021 Accepted: 02 June 2021

Published: 22 June 2021

Citation:

Gilmartin MR and Ferrara NC (2021) Pituitary Adenylate Cyclase-Activating Polypeptide in Learning and Memory. Front. Cell. Neurosci. 15:663418. doi: 10.3389/fncel.2021.663418

\section{Pituitary Adenylate Cyclase-Activating Polypeptide in Learning and Memory}

\author{
Marieke R. Gilmartin ${ }^{*}$ and Nicole C. Ferrara ${ }^{2}$ \\ ${ }^{1}$ Marquette University, Milwaukee, WI, United States, ${ }^{2}$ Rosalind Franklin University of Medicine and Science, North Chicago, \\ IL, United States
}

Pituitary adenylate cyclase-activating polypeptide (PACAP) is a highly conserved neuropeptide that regulates neuronal physiology and transcription through Gs/Gqcoupled receptors. Its actions within hypothalamic, limbic, and mnemonic systems underlie its roles in stress regulation, affective processing, neuroprotection, and cognition. Recently, elevated PACAP levels and genetic disruption of PAC1 receptor signaling in humans has been linked to maladaptive threat learning and pathological stress and fear in post-traumatic stress disorder (PTSD). PACAP is positioned to integrate stress and memory in PTSD for which memory of the traumatic experience is central to the disorder. However, PACAP's role in memory has received comparatively less attention than its role in stress. In this review, we consider the evidence for PACAP-PAC1 receptor signaling in learning and plasticity, discuss emerging data on sex differences in PACAP signaling, and raise key questions for further study toward elucidating the contribution of PACAP to adaptive and maladaptive fear learning.

Keywords: PACAP, learning, working memory, fear, anxiety, cognition, sex, PTSD

\section{INTRODUCTION}

The salient experiences of our daily life create memories that form the narrative of our self. These memories enrich our connections with others and guide our decisions and behavior, but if born out of pain and trauma, can be debilitating. Intrusive, terrifying memories that are difficult to extinguish or that generalize to non-threatening situations are the hallmark of post-traumatic stress disorder (PTSD), a complex disorder with a lifetime prevalence of about 8\% (Kessler et al., 1995; Kilpatrick et al., 2013). PTSD is characterized by altered stress reactivity, generalized fear to non-threatening cues and situations, and is more prevalent in females (Kessler et al., 1995; Kilpatrick et al., 2013). Recently, the neuropeptide pituitary adenylate cyclase-activating polypeptide (PACAP) has been linked to PTSD (Ressler et al., 2011; Almli et al., 2013; Uddin et al., 2013). This link has been attributed to the role that PACAP plays in regulating the somatic and affective components of chronic stress, discussed in excellent reviews (Hammack and May, 2015; King et al., 2017b; Miles and Maren, 2019). However, PACAP's role in memory has received comparatively less attention yet may also contribute to PTSD for which memory of the traumatic experience is central to the disorder. Here, we briefly review the literature supporting a role for PACAP in memory formation and discuss avenues for further investigation. 


\section{PACAP, AN OVERVIEW}

Pituitary adenylate cyclase-activating polypeptide is a highly conserved pleiotropic neuropeptide in the vasoactive intestinal peptide (VIP)/secretin/glucagon family that modulates several physiological functions in the periphery and central nervous system via class B G-protein coupled receptors (Miyata et al., 1989, 1990; Arimura et al., 1991; Piggins et al., 1996; Arimura, 1998; Vaudry et al., 2009). In the brain, the 38 -amino acid form of PACAP predominates (Arimura, 1998), and PACAP-38 and its receptors are widely expressed in circuits involved in memory, stress, and affect (Shioda et al., 1997; Hannibal, 2002; Joo et al., 2004; Condro et al., 2016). PACAP modulates neuronal function via the PACAP-specific high-affinity receptor PAC1 and the VPAC1 and VPAC2 receptors, which have similar affinity for PACAP and VIP. These receptors are coupled to Gas, but PAC1 can also signal through G $\alpha$ (Spengler et al., 1993; Dickson and Finlayson, 2009; Vaudry et al., 2009; Harmar et al., 2012). Thus, PACAP can regulate the neuronal excitability and synaptic plasticity underlying memory and cognition through a diverse set of cAMP-mediated intracellular signaling (for a review see Johnson et al., 2019).

\section{DISTRIBUTED MEMORY SYSTEMS}

A role for PACAP in learning and memory was evident from early examinations of mice lacking the PAC1 receptor (PAC1R). Genetic deletion of PAC1R either globally or in the forebrain produced mild to severe impairments in certain forms of hippocampus-dependent learning (Sauvage et al., 2000; Otto et al., 2001a,b). Contextual fear conditioning, an associative paradigm in which subjects learn to associate the spatial configuration of environmental cues with a footshock, was impaired, while other hippocampus-dependent learning tasks, the Morris water maze and social transmission of food preference were unaffected. Hippocampus-independent cued fear conditioning was also unaffected by the loss of PAC1R signaling in the same study. Global knockouts displayed anxietylike behavior and altered stress reactivity, which is consistent with PACAP's role in HPA axis regulation, but which could affect the conditional response of freezing used to assess memory in rodent fear conditioning. Thus, it is important that the forebrainspecific knockouts, which showed the same memory deficit, did not differ from wild-type controls in locomotor activity or anxiety-like activity in the open field or elevated plus maze (Otto et al., 2001b). Mice lacking the PACAP peptide also showed impaired contextual fear memory as well as deficits in novel object recognition (Takuma et al., 2014). However, these mice exhibit a wide range of altered behavior (reviewed in Hashimoto et al., 2006). Some of these behaviors could be ameliorated with environmental enrichment early in life, but not in adulthood, suggesting that PACAP's role in neural development may contribute to abnormal behaviors in PACAP deficient mice (Ishihama et al., 2010; Takuma et al., 2014). Nonetheless, exogenous delivery of PACAP intracerebroventricularly into adult rats enhanced the consolidation of a passive avoidance memory at low doses (Sacchetti et al., 2001) and temporarily impaired contextual fear memory at high doses (Meloni et al., 2016, 2018). These studies demonstrate a role for forebrain PACAP in contextual fear learning and suggest that PAC1R signaling may be preferentially engaged by aversive events.

More recently, behavioral pharmacology studies have identified specific brain regions where PACAP contributes to aversive memory or its extinction. These include the hippocampus, amygdala, and prelimbic cortex. In the hippocampus, the consolidation of contextual fear memory was enhanced by PACAP and impaired by the PAC1R antagonist PACAP6-38, when injected immediately after training (Schmidt et al., 2015). Hippocampal PACAP also contributes to fear extinction, while amygdala PACAP is needed for contextual fear memory but not its extinction (Schmidt et al., 2015). The subregional specificity of PACAP's effects in the hippocampus remain to be determined. The hippocampus is functionally heterogeneous with unique output connectivity along its dorsalventral axis (Dong et al., 2009). These studies targeted dorsal hippocampus and given the importance of ventral hippocampus to affective behavior and learning, future work should examine ventral hippocampal PACAP. PACAP also participates in the formation of trace fear memory, a form of cued fear learning dependent on the prelimbic cortex and hippocampus in addition to the amygdala (Kirry et al., 2018). Trace conditioning requires the association of a cue and shock separated in time, and linking these events requires sustained neuronal activity in prelimbic cortex (Baeg et al., 2001; Gilmartin and McEchron, 2005; Gilmartin et al., 2013b, 2014). Prelimbic injection of PACAP6-38 prior to training impaired the formation of the cued memory in females, but not males (Kirry et al., 2018). This sex difference, discussed below, may provide insight into the genetic link between PAC1R and PTSD, for which women with a genetic polymorphism in the PAC1R gene exhibit enhanced reactivity to threat-predictive cues (Ressler et al., 2011). The prefrontal cortex is also needed for aspects of contextual fear learning (Gilmartin and Helmstetter, 2010; Gilmartin et al., 2013a; Rozeske et al., 2015; Heroux et al., 2017; Twining et al., 2020), but PAC1R antagonism did not affect the contextual fear memory formed alongside the cued fear memory in trace conditioning (Kirry et al., 2018). Nor did the manipulation affect a non-aversive spatial-working memory T-maze task in either sex. These data suggest that PAC1R signaling contributes to prefrontal mechanisms of working memory or sustained attention required for predicting threat based on available cues. Together, these studies demonstrate a role for PACAP signaling in learning and memory and point to site-specific engagement of PACAP in cued and contextual fear.

\section{CELLULAR AND SYNAPTIC PHYSIOLOGY}

The regulation of synaptic glutamatergic signaling and the production of new proteins for long-term synaptic stabilization 
are the basis of the cellular consolidation of memory, a process that generally concludes within a few hours after training (McGaugh, 2000; Asok et al., 2019). Adenylate cyclase/cAMPdriven intracellular signaling leading to CREB-mediated gene transcription is critical for the formation of long-term memories (Kandel et al., 2014; Asok et al., 2019). PACAP's namesake ability to activate these signaling cascades underlies its role in memory. In hippocampal circuits, PACAP modulates synaptic and evoked NMDA- and AMPA-mediated currents via PKA or PLC/PKC (Roberto and Brunelli, 2000; Roberto et al., 2001; Ciranna and Cavallaro, 2003; Yaka et al., 2003; Macdonald et al., 2005; Costa et al., 2009; Pecoraro et al., 2017). PACAP-dependent phosphorylation of NMDA receptor subunits promotes mossy fiber long-term potentiation (LTP), a cellular correlate of learning and memory, and LTP is impaired in mice lacking PACAP or PAC1R (Otto et al., 2001a; Matsuyama et al., 2003). PACAP's effects on plasticity are dose-dependent, with higher doses exerting inhibitory effects on hippocampal synaptic transmission via VPAC signaling (Costa et al., 2009), which reflects its dose-dependent effects on hippocampus-dependent fear memory (Sacchetti et al., 2001; Meloni et al., 2016). It is important to note that temperature is an important factor in the physiological investigation of PACAP. While lower temperatures (e.g., 21$24^{\circ} \mathrm{C}$ ) are useful for slowing down the fast ion channel kinetics linked to PAC1R activation (Johnson et al., 2019), they can alter other measures of excitability and interfere with PAC1R endosomal signaling (Merriam et al., 2013). Moreover, the majority of existing hippocampal work has focused on CA1 and CA3, but PAC1R is expressed also in the dentate gyrus (Jaworski and Proctor, 2000; Joo et al., 2004). Recent work has shown that PACAP-PAC1R activation drives CREB-mediated transcription and promotes excitability of DG granule cells (Johnson et al., 2019; Johnson R. et al., 2020; Johnson R. L. et al., 2020).

Pituitary adenylate cyclase-activating polypeptide has dose-, receptor-, and circuit-specific effects on physiology in other brain areas, which highlights the potential ways in which PACAP can affect learning within a distributed network. In the amygdala, PACAP increases AMPA-mediated currents at BLA-CeA synapses via VPAC1 (Cho et al., 2012) and increases GABA release via PAC1R (Varodayan et al., 2019), mechanisms that underlie affective behavioral responses to chronic stress or pain. In the central nucleus of the amygdala, fear conditioning drives expression of the plasticity-related protein Arc and intracerebroventricular infusion of PACAP enhances this expression (Meloni et al., 2018). Arc, whose translation is regulated by PKA activity (Bloomer et al., 2008), is critical to several cellular processes supporting memory and cognition (e.g., Nikolaienko et al., 2018). PACAP's contribution to synaptic plasticity in cortical systems is not clear. Given the selective role for prelimbic PAC1R signaling in trace cued, but not contextual, memory (Kirry et al., 2018), PACAP may act on working-memory or sustained attention mechanisms. One candidate mechanism is the regulation of GluN2B-containing NMDARs, which promote recurrent activity in cortical circuits (Wang et al., 2013) and which are needed for trace cued, but not contextual fear learning in the prefrontal cortex and hippocampus (Gao et al., 2010; Gilmartin et al., 2013a). PACAP has been shown to phosphorylate the GluN2B subunit in the hippocampus and hypothalamus to regulate glutamatergic signaling (Yaka et al., 2003; Resch et al., 2014).

Pituitary adenylate cyclase-activating polypeptide can also influence memory via modulation of intrinsic physiology (see Open Questions) and via developmental maturation of memory circuits (reviewed in Shen et al., 2013). For example, developmental knockout of VPAC2 which is sensitive to both VIP and PACAP prevented the formation of fear extinction memory in adulthood (Ago et al., 2017). Importantly, VPAC2-KO mice had reduced cell size and dendritic branching in the prelimbic cortex, morphological changes similar to those observed after chronic corticosterone exposure and chronic stress, conditions which also produce fear extinction deficits (Wellman, 2001; Radley et al., 2004, 2006; Moench and Wellman, 2017; reviewed in Wellman et al., 2020). Whether impaired extinction in VPAC2$\mathrm{KO}$ mice is a consequence of altered prefrontal morphology or lack of PACAP/VIP signaling at VPAC2 in the prefrontalamygdala circuit during extinction learning remains to be determined. Nonetheless, these neuropeptides are necessary for proper neural maturation, and pathological disruptions in PACAP signaling during critical developmental windows could thus affect adult cognition by altering the development of memory-related circuits. Although we are only beginning to elucidate the diverse mechanisms by which PACAP affects learning and memory, the significant work on the diversity of PACAP signaling in stress-related behaviors provides a useful foundation for rapid progress in this effort (Hammack and May, 2015; Johnson et al., 2019; Ferrara and Gilmartin, 2020).

\section{SEX DIFFERENCES}

The work above implicates PACAP and PAC1R in neuroplasticity and memory and suggests that endogenous PACAP released during salient, aversive events contributes to memories for threat-predictive cues and contexts. Therefore, vulnerabilities in PACAP signaling may contribute to pathological fear in PTSD through its roles in learning and in mediating traumatic stress responses. Further investigation of the PACAP-PTSD link requires inclusion of female subjects, not only because females have largely been excluded from preclinical study, but also because of a sex-specific link between PACAP and PTSD. A single-nucleotide polymorphism (SNP) in the adcyap1r1 gene encoding PAC1R is associated with symptom severity in women, but not men; altered DNA methylation of the same gene is associated with PTSD in both sexes (Ressler et al., 2002; Almli et al., 2013). The risk allele for PTSD is also associated with symptom severity in GAD females, but not males (Ross et al., 2020). The SNP is located in an estrogenresponse element (ERE), and the nucleotide change interferes with estradiol-estrogen receptor alpha binding the ERE, leading to a decrease in receptor expression (Mercer et al., 2016). This points to a potential mechanism of vulnerability in women. Indeed, several labs are actively examining how PACAP in the 
BNST and hypothalamic stress circuits regulates the affective response to stress in male and female rodents (King et al., 2017a,b; Ramikie and Ressler, 2018), and additional mechanistic insight may come from examination of sex differences in autonomic regulation by PACAP (Nakamachi et al., 2016). This work complements that of Bangasser, Valentino, and others detailing sex differences in the corticotropin-releasing factor (CRF) system and brainstem arousal systems [for excellent reviews, see Bangasser and Valentino (2014); Valentino and Bangasser (2016); Bangasser et al. (2019)].

Little is known about sex differences in PACAP's contribution to memory. Recent work showed that prelimbic PACAP participates in trace cued fear learning in females, but not males, and that mRNA levels for PAC1R are higher in females than males and further modulated by the estrous cycle (Kirry et al., 2018). Recently, Rajbhandari et al. (2021) reported increased fear generalization and impaired extinction in males, but not females, following viral deletion of PAC1R in the medial intercalated cells of the amygdala, a region involved in the suppression of fear following extinction (Duvarci and Pare, 2014). Females in that study showed a reduced asymptotic level of fear during acquisition. These behavioral results suggest that PACAP signaling exerts sex and region-specific modulation of fear memories. In humans, the PTSD-related PAC1R risk allele is associated with enhanced startle to threat-related cues, impaired fear and safety discrimination, and altered hippocampal and amygdala reactivity in fear conditioning (Ressler et al., 2011; Jovanovic et al., 2013; Stevens et al., 2014). In children, females with the risk allele showed enhanced fear responding to threat-related cues 1 year after conditioning (Jovanovic et al., 2020). While these clinical studies implicate associative learning processes in the PAC1R-PTSD link, it is difficult to distinguish the unique contributions of associative learning vs stress reactivity. Preclinical investigations are critical in this endeavor.

\section{OPEN QUESTIONS}

Pituitary adenylate cyclase-activating polypeptide contributes to learning and memory under salient, usually aversive conditions. The diversity of its neural function places this pleiotropic signaling peptide in the company of several peptide factors, such as CRF and estradiol, that have a wide range of function beyond that for which they were initially characterized (Hupalo et al., 2019; Taxier et al., 2020). This diversity likely underlies the influence that PACAP dysregulation appears to have in psychiatric illness, but also makes it challenging to determine the nature of that relationship. Here, we raise a few open questions to guide further investigation.

\section{Open Question 1: Is PACAP's Role in Learning Selective for Aversive Episodic Memory?}

Disruption of PAC1R signaling affects the formation of associative fear memories dependent on episodic memory systems, such as contextual fear or trace fear conditioning, but leaves standard delay cued conditioning and spatial learning largely intact. Interestingly, the amnesiac gene in drosophila, which codes for a putative PACAP homolog, AMN, is necessary for odor-shock associative memory (Quinn et al., 1979; Feany and Quinn, 1995; Turrel et al., 2018). While the receptor target(s) by which AMN mediates memory is unclear, the parallels in these behavioral observations raise the possibility that PACAP is selective for aversive learning; however, its role in appetitive or other non-aversive learning is largely untested. Thus, to determine PACAP selectivity to certain forms of memory, its contribution to non-aversive memory needs to be clarified. Importantly, PACAP and PAC1R manipulations in the mature circuit are needed to rule out learning deficits due to aberrant neural development of healthy memory circuits for which PACAP is implicated. To this point, the role for AMN in the development of associative memory systems was recently dissociated from its role in adult learning (Turrel et al., 2018).

\section{Open Question 2: What Aspect of an Aversive Experience Recruits PACAP Signaling?}

Pituitary adenylate cyclase-activating polypeptide is mobilized by repeated or chronic stressors or by persistent neuropathic pain states (Dickinson and Fleetwood-Walker, 1999; Mustafa, 2013), but release conditions in learning networks during relatively brief aversive events in fear conditioning are unknown. PACAP-expressing cells are found throughout learning circuits (Hannibal, 2002; Condro et al., 2016), many of which robustly respond to shock delivery. One possibility is that the aversive shock reinforcer may trigger the corelease of PACAP at glutamatergic terminals, facilitating cAMP-mediated signaling in support of robust fear memory. Alternatively, any sufficiently salient or arousing experience may mobilize PACAP and promote the consolidation of memory. The development of tools that allow accurate measurement of peptide release in vivo provide the circuitlevel resolution needed to determine when and where PACAP is released during learning (Muller et al., 2014; Al-Hasani et al., 2018).

\section{Open Question 3: What Are the Unique Peptide-Receptor Signaling Contributions to Learning and Memory?}

The unique contributions of PACAP and VIP at PAC1 and $\mathrm{VPAC} 1 / 2$ receptors in learning and memory are poorly understood. For instance, VPAC2 receptors have partially overlapping distribution patterns in several regions important for learning and memory (Lee et al., 2010), and developmental manipulation of VPAC2 affects extinction learning in adulthood (Ago et al., 2017). Pharmacological dissociation of PACAP actions at PAC1R and VPAC2 is difficult as both are a target of the PAC1R antagonist PACAP6-38. Plus, as mentioned earlier, mechanistic dissection of these peptides in vitro is sensitive to experimental parameters such as temperature. Thus, new small molecule antagonists as well as gene-editing tools will 
be invaluable in revealing the rich complexity of mnemonic regulation by these peptides.

\section{Open Question 4: Does PACAP Bias Allocation of Specific Circuits Into Memory?}

One intriguing, but speculative, role for PACAP in memory is to bias the allocation of cells or circuits into memory as a consequence of psychological stress or aversive experience (Kondo et al., 1997). Neuronal excitability at the time of learning determines which neurons are allocated to the memory trace (Yiu et al., 2014; Cai et al., 2016; Sehgal et al., 2018; Josselyn and Tonegawa, 2020). In the amygdala, cells with reduced afterhyperpolarization (AHP) and increased CREB phosphorylation immediately prior to training are recruited into a fear memory (Yiu et al., 2014). PACAP reduces the slow AHP calcium-activated potassium current $\mathrm{SI}_{A H P}$ via $\mathrm{cAMP} / \mathrm{PKA}$ to increase excitability and action potential firing in hippocampal CA1 and neocortical neurons (Hu et al., 2011; Taylor et al., 2014). PACAP-elicited firing and PKA-dependent phosphorylation of CREB drive CREB-mediated transcription (Baxter et al., 2011). PACAP affects excitability and firing in a circuit-specific manner (e.g., Hurley et al., 2019) and intrinsic properties can be modified by experience (Sehgal et al., 2013; Dunn and Kaczorowski, 2019). Thus, PACAP released during stressful events or elevated PACAP following chronic stress or pain could influence which circuits are recruited into a memory trace. Addressing this possibility will shed light on how altered PACAP-PAC1R signaling in susceptible individuals corresponds with altered threat-associated memory in PTSD.

\section{REFERENCES}

Ago, Y., Hayata-Takano, A., Kawanai, T., Yamauchi, R., Takeuchi, S., Cushman, J. D., et al. (2017). Impaired extinction of cued fear memory and abnormal dendritic morphology in the prelimbic and infralimbic cortices in VPAC2 receptor (VIPR2)-deficient mice. Neurobiol. Learn. Mem. 145, 222-231. doi: 10.1016/j.nlm.2017.10.010

Al-Hasani, R., Wong, J. T., Mabrouk, O. S., McCall, J. G., Schmitz, G. P., PorterStransky, K. A., et al. (2018). In vivo detection of optically-evoked opioid peptide release. eLife 7:e36520.

Almli, L. M., Mercer, K. B., Kerley, K., Feng, H., Bradley, B., Conneely, K. N., et al. (2013). ADCYAP1R1 genotype associates with post-traumatic stress symptoms in highly traumatized African-American females. Am. J. Med. Genet. B Neuropsychiatr. Genet. 162B, 262-272. doi: 10.1002/ajmg.b.3 2145

Arimura, A. (1998). Perspectives on pituitary adenylate cyclase activating polypeptide (PACAP) in the neuroendocrine, endocrine, and nervous systems. Jpn. J. Physiol. 48, 301-331. doi: 10.2170/jjphysiol.48.301

Arimura, A., Somogyvari-Vigh, A., Miyata, A., Mizuno, K., Coy, D. H., and Kitada, C. (1991). Tissue distribution of PACAP as determined by RIA: highly abundant in the rat brain and testes. Endocrinology 129, 2787-2789. doi: 10.1210/endo129-5-2787

Asok, A., Leroy, F., Rayman, J. B., and Kandel, E. R. (2019). Molecular mechanisms of the memory trace. Trends Neurosci. 42, 14-22. doi: 10.1016/j.tins.2018.10. 005

Baeg, E. H., Kim, Y. B., Jang, J., Kim, H. T., Mook-Jung, I., and Jung, M. W. (2001). Fast spiking and regular spiking neural correlates of fear conditioning in the medial prefrontal cortex of the rat. Cereb. Cortex 11, 441-451. doi: $10.1093 /$ cercor/11.5.441

\section{CONCLUDING REMARKS}

Pituitary adenylate cyclase-activating polypeptide is a pleiotropic neuropeptide whose diverse signaling underlies its diversity of function including neural development, neuroprotection, stress regulation, autonomic activation, affective behavior, and memory. This in turn highlights the therapeutic potential of this peptide and receptor modulations, a potential that is discussed in this Research Topic and reflected in recent efforts to develop nonpeptide small molecule compounds to selectively target PACAP receptors (Beebe et al., 2008; Takasaki et al., 2018). The link between PACAP-PAC1R and pathological fear learning and stress dysregulation in PTSD suggests another potential therapeutic use for such treatments. Realization of this potential requires continued efforts to address the role of PACAP in learning and in the complex interactions of stress and sex on memory.

\section{AUTHOR CONTRIBUTIONS}

MG and NF wrote and edited the manuscript. Both authors contributed to the article and approved the submitted version.

\section{FUNDING}

This work was supported by the National Institutes of Health (R15MH118601 to MG; F32MH122092 to NF) and the Charles E. Kubly Mental Health Center at Marquette University. Support for Open Access fees was provided by Marquette University.

Bangasser, D. A., and Valentino, R. J. (2014). Sex differences in stress-related psychiatric disorders: neurobiological perspectives. Front. Neuroendocrinol. 35, 303-319. doi: 10.1016/j.yfrne.2014.03.008

Bangasser, D. A., Eck, S. R., and Ordones Sanchez, E. (2019). Sex differences in stress reactivity in arousal and attention systems. Neuropsychopharmacology 44, 129-139. doi: 10.1038/s41386-018-0137-2

Baxter, P. S., Martel, M. A., McMahon, A., Kind, P. C., and Hardingham, G. E. (2011). Pituitary adenylate cyclase-activating peptide induces long-lasting neuroprotection through the induction of activity-dependent signaling via the cyclic AMP response element-binding protein-regulated transcription coactivator 1. J. Neurochem. 118, 365-378. doi: 10.1111/j.1471-4159.2011.0 7330.x

Beebe, X., Darczak, D., Davis-Taber, R. A., Uchic, M. E., Scott, V. E., Jarvis, M. F., et al. (2008). Discovery and SAR of hydrazide antagonists of the pituitary adenylate cyclase-activating polypeptide (PACAP) receptor type 1 (PAC1-R). Bioorg. Med. Chem. Lett. 18, 2162-2166. doi: 10.1016/j.bmcl.2008.01.052

Bloomer, W. A., VanDongen, H. M., and VanDongen, A. M. (2008). Arc/Arg3.1 translation is controlled by convergent N-methyl-D-aspartate and Gs-coupled receptor signaling pathways. J. Biol. Chem. 283, 582-592. doi: 10.1074/jbc. m702451200

Cai, D. J., Aharoni, D., Shuman, T., Shobe, J., Biane, J., Song, W., et al. (2016). A shared neural ensemble links distinct contextual memories encoded close in time. Nature 534, 115-118. doi: 10.1038/nature17955

Cho, J. H., Zushida, K., Shumyatsky, G. P., Carlezon, W. A., Meloni, E. G., and Bolshakov, V. Y. (2012). Pituitary adenylate cyclase-activating polypeptide induces postsynaptically expressed potentiation in the intra-amygdala circuit. J. Neurosci. 32, 14165-14177. doi: 10.1523/jneurosci.1402-12.2012

Ciranna, L., and Cavallaro, S. (2003). Opposing effects by pituitary adenylate cyclase-activating polypeptide and vasoactive intestinal peptide 
on hippocampal synaptic transmission. Exp. Neurol. 184, 778-784. doi: 10.1016/s0014-4886(03)00300-5

Condro, M. C., Matynia, A., Foster, N. N., Ago, Y., Rajbhandari, A. K., Van, C., et al. (2016). High-resolution characterization of a PACAP-EGFP transgenic mouse model for mapping PACAP-expressing neurons. J. Comp. Neurol. 524, 3827-3848. doi: 10.1002/cne.24035

Costa, L., Santangelo, F., Li Volsi, G., and Ciranna, L. (2009). Modulation of AMPA receptor-mediated ion current by pituitary adenylate cyclase-activating polypeptide (PACAP) in CA1 pyramidal neurons from rat hippocampus. Hippocampus 19, 99-109. doi: 10.1002/hipo.20488

Dickinson, T., and Fleetwood-Walker, S. M. (1999). VIP and PACAP: very important in pain? Trends Pharmacol. Sci. 20, 324-329. doi: 10.1016/s01656147(99)01340-1

Dickson, L., and Finlayson, K. (2009). VPAC and PAC receptors: from ligands to function. Pharmacol. Ther. 121, 294-316. doi: 10.1016/j.pharmthera.2008.11. 006

Dong, H. W., Swanson, L. W., Chen, L., Fanselow, M. S., and Toga, A. W. (2009). Genomic-anatomic evidence for distinct functional domains in hippocampal field CA1. Proc. Natl. Acad. Sci. U. S. A. 106, 11794-11799. doi: 10.1073/pnas. 0812608106

Dunn, A. R., and Kaczorowski, C. C. (2019). Regulation of intrinsic excitability: roles for learning and memory, aging and Alzheimer's disease, and genetic diversity. Neurobiol. Learn. Mem. 164:107069. doi: 10.1016/j.nlm.2019.107069

Duvarci, S., and Pare, D. (2014). Amygdala microcircuits controlling learned fear. Neuron 82, 966-980. doi: 10.1016/j.neuron.2014.04.042

Feany, M. B., and Quinn, W. G. (1995). A neuropeptide gene defined by the Drosophila memory mutant amnesiac. Science 268, 869-873. doi: 10.1126/ science. 7754370

Ferrara, N. C., and Gilmartin, M. R. (2020). "Pituitary adenylate cyclase-activating polypeptide (PACAP) in stress, pain, and learning," in Handbook of Amygdala Structure and Function, ed. J. H. Urban (Amsterdam: Elsevier).

Gao, C., Gill, M. B., Tronson, N. C., Guedea, A. L., Guzman, Y. F., Huh, K. H., et al. (2010). Hippocampal NMDA receptor subunits differentially regulate fear memory formation and neuronal signal propagation. Hippocampus 20, 1072-1082. doi: 10.1002/hipo.20705

Gilmartin, M. R., and Helmstetter, F. J. (2010). Trace and contextual fear conditioning require neural activity and NMDA receptor-dependent transmission in the medial prefrontal cortex. Learn. Mem. 17, 289-296. doi: $10.1101 / \mathrm{lm} .1597410$

Gilmartin, M. R., and McEchron, M. D. (2005). Single neurons in the medial prefrontal cortex of the rat exhibit tonic and phasic coding during trace fear conditioning. Behav. Neurosci. 119, 1496-1510. doi: 10.1037/0735-7044.119.6. 1496

Gilmartin, M. R., Balderston, N. L., and Helmstetter, F. J. (2014). Prefrontal cortical regulation of fear learning. Trends Neurosci. 37, 455-464. doi: 10.1016/j.tins. 2014.05.004

Gilmartin, M. R., Kwapis, J. L., and Helmstetter, F. J. (2013a). NR2A-and NR2B-containing NMDA receptors in the prelimbic medial prefrontal cortex differentially mediate trace, delay, and contextual fear conditioning. Learn. Mem. 20, 290-294. doi: 10.1101/lm.030510.113

Gilmartin, M. R., Miyawaki, H., Helmstetter, F. J., and Diba, K. (2013b). Prefrontal activity links nonoverlapping events in memory. J. Neurosci. 33, 10910-10914. doi: 10.1523/jneurosci.0144-13.2013

Hammack, S. E., and May, V. (2015). Pituitary adenylate cyclase activating polypeptide in stress-related disorders: data convergence from animal and human studies. Biol. Psychiatry 78, 167-177. doi: 10.1016/j.biopsych.2014.12. 003

Hannibal, J. (2002). Pituitary adenylate cyclase-activating peptide in the rat central nervous system: an immunohistochemical and in situ hybridization study. J. Comp. Neurol. 453, 389-417. doi: 10.1002/cne.10418

Harmar, A. J., Fahrenkrug, J., Gozes, I., Laburthe, M., May, V., Pisegna, J. R., et al. (2012). Pharmacology and functions of receptors for vasoactive intestinal peptide and pituitary adenylate cyclase-activating polypeptide: IUPHAR review 1. Br. J. Pharmacol. 166, 4-17. doi: 10.1111/j.1476-5381.2012.01871.x

Hashimoto, H., Shintani, N., and Baba, A. (2006). New insights into the central PACAPergic system from the phenotypes in PACAP- and PACAP receptorknockout mice. Ann. N. Y. Acad. Sci. 1070, 75-89. doi: 10.1196/annals.1317. 038
Heroux, N. A., Robinson-Drummer, P. A., Sanders, H. R., Rosen, J. B., and Stanton, M. E. (2017). Differential involvement of the medial prefrontal cortex across variants of contextual fear conditioning. Learn. Mem. 24, 322-330. doi: 10. $1101 / \operatorname{lm} .045286 .117$

Hu, E., Demmou, L., Cauli, B., Gallopin, T., Geoffroy, H., Harris-Warrick, R. M., et al. (2011). VIP, CRF, and PACAP act at distinct receptors to elicit different cAMP/PKA dynamics in the neocortex. Cereb. Cortex 21, 708-718. doi: 10. 1093/cercor/bhq143

Hupalo, S., Bryce, C. A., Bangasser, D. A., Berridge, C. W., Valentino, R. J., and Floresco, S. B. (2019). Corticotropin-releasing factor (CRF) circuit modulation of cognition and motivation. Neurosci. Biobehav. Rev. 103, 50-59. doi: 10.1016/ j.neubiorev.2019.06.010

Hurley, M. M., Robble, M. R., Callan, G., Choi, S., and Wheeler, R. A. (2019). Pituitary adenylate cyclase-activating polypeptide (PACAP) acts in the nucleus accumbens to reduce hedonic drive. Int. J. Obes. 43, 928-932. doi: 10.1038/ s41366-018-0154-6

Ishihama, T., Ago, Y., Shintani, N., Hashimoto, H., Baba, A., Takuma, K., et al. (2010). Environmental factors during early developmental period influence psychobehavioral abnormalities in adult PACAP-deficient mice. Behav. Brain Res. 209, 274-280. doi: 10.1016/j.bbr.2010.02.009

Jaworski, D. M., and Proctor, M. D. (2000). Developmental regulation of pituitary adenylate cyclase-activating polypeptide and PAC(1) receptor mRNA expression in the rat central nervous system. Brain Res. Dev. Brain Res. 120, 27-39. doi: 10.1016/s0165-3806(99)00192-3

Johnson, G. C., May, V., Parsons, R. L., and Hammack, S. E. (2019). Parallel signaling pathways of pituitary adenylate cyclase activating polypeptide (PACAP) regulate several intrinsic ion channels. Ann. N. Y. Acad. Sci. 1455, 105-112. doi: $10.1111 /$ nyas. 14116

Johnson, R. L., Parsons, G. C., May, V., and Hammack, S. E. (2020). Pituitary adenylate cyclase-activating polypeptide-induced $\mathrm{PACl}$ receptor internalization and recruitment of MEK/ERK signaling enhance excitability of dentate gyrus granule cells. Am. J. Physiol. Cell Physiol. 318, C870-C878.

Johnson, R., Parsons, G. C., May, V., and Hammack, S. E. (2020). The role of pituitary adenylate cyclase-activating polypeptide (PACAP) signaling in the hippocampal dentate Gyrus. Front. Cell. Neurosci. 14:111.

Joo, K. M., Chung, Y. H., Kim, M. K., Nam, R. H., Lee, B. L., Lee, K. H., et al. (2004). Distribution of vasoactive intestinal peptide and pituitary adenylate cyclaseactivating polypeptide receptors (VPAC1, VPAC2, and PAC1 receptor) in the rat brain. J. Comp. Neurol. 476, 388-413. doi: 10.1002/cne.20231

Josselyn, S. A., and Tonegawa, S. (2020). Memory engrams: recalling the past and imagining the future. Science 367:eaaw4325. doi: 10.1126/science.aaw4325

Jovanovic, T., Norrholm, S. D., Davis, J., Mercer, K. B., Almli, L., Nelson, A., et al. (2013). PAC1 receptor (ADCYAP1R1) genotype is associated with darkenhanced startle in children. Mol. Psychiatry 18, 742-743. doi: 10.1038/mp. 2012.98

Jovanovic, T., Stenson, A. F., Thompson, N., Clifford, A., Compton, A., Minton, S., et al. (2020). Impact of ADCYAP1R1 genotype on longitudinal fear conditioning in children: interaction with trauma and sex. Neuropsychopharmacology 45, 1603-1608. doi: 10.1038/s41386-020-0748-2

Kandel, E. R., Dudai, Y., and Mayford, M. R. (2014). The molecular and systems biology of memory. Cell 157, 163-186. doi: 10.1016/j.cell.2014.03.001

Kessler, R. C., Sonnega, A., Bromet, E., Hughes, M., and Nelson, C. B. (1995). Posttraumatic stress disorder in the national comorbidity survey. Arch. Gen. Psychiatry 52, 1048-1060. doi: 10.1001/archpsyc.1995.03950240066012

Kilpatrick, D. G., Resnick, H. S., Milanak, M. E., Miller, M. W., Keyes, K. M., and Friedman, M. J. (2013). National estimates of exposure to traumatic events and PTSD prevalence using DSM-IV and DSM-5 criteria. J. Trauma Stress 26, 537-547. doi: $10.1002 /$ jts. 21848

King, S. B., Lezak, K. R., O’Reilly, M., Toufexis, D. J., Falls, W. A., Braas, K., et al. (2017a). The effects of prior stress on anxiety-like responding to intraBNST pituitary adenylate cyclase activating polypeptide in male and female rats. Neuropsychopharmacology 42, 1679-1687. doi: 10.1038/npp.2017.16

King, S. B., Toufexis, D. J., and Hammack, S. E. (2017b). Pituitary adenylate cyclase activating polypeptide (PACAP), stress, and sex hormones. Stress 20, 465-475. doi: 10.1080/10253890.2017.1336535

Kirry, A. J., Herbst, M. R., Poirier, S. E., Maskeri, M. M., Rothwell, A. C., Twining, R. C., et al. (2018). Pituitary adenylate cyclase-activating polypeptide (PACAP) signaling in the prefrontal cortex modulates cued fear learning, but not spatial 
working memory, in female rats. Neuropharmacology 133, 145-154. doi: 10. 1016/j.neuropharm.2018.01.010

Kondo, T., Tominaga, T., Ichikawa, M., and Iijima, T. (1997). Differential alteration of hippocampal synaptic strength induced by pituitary adenylate cyclase activating polypeptide-38 (PACAP-38). Neurosci. Lett. 221, 189-192. doi: 10. 1016/s0304-3940(96)13323-1

Lee, J. C., Cho, Y. J., Kim, J., Kim, N., Kang, B. G., Cha, C. I., et al. (2010). Regionspecific changes in the immunoreactivity of vasoactive intestinal peptide and pituitary adenylate cyclase-activating polypeptide receptors (VPAC2, and PAC1 receptor) in the aged rat brains. Brain Res. 1351, 32-40. doi: 10.1016/j.brainres. 2010.06.048

Macdonald, D. S., Weerapura, M., Beazely, M. A., Martin, L., Czerwinski, W., Roder, J. C., et al. (2005). Modulation of NMDA receptors by pituitary adenylate cyclase activating peptide in CA1 neurons requires $\mathrm{G}$ alpha $\mathrm{q}$, protein kinase C, and activation of Src. J. Neurosci. 25, 11374-11384. doi: 10.1523/jneurosci. 3871-05.2005

Matsuyama, S., Matsumoto, A., Hashimoto, H., Shintani, N., and Baba, A. (2003). Impaired long-term potentiation in vivo in the dentate gyrus of pituitary adenylate cyclase-activating polypeptide (PACAP) or PACAP type 1 receptormutant mice. Neuroreport 14, 2095-2098. doi: 10.1097/00001756-20031114000017

McGaugh, J. L. (2000). Memory-a century of consolidation. Science 287, 248-251. doi: 10.1126/science.287.5451.248

Meloni, E. G., Kaye, K. T., Venkataraman, A., and Carlezon, W. A. (2018). PACAP increases Arc/Arg 3.1 expression within the extended amygdala after fear conditioning in rats. Neurobiol. Learn. Mem. 157, 24-34. doi: 10.1016/j.nlm. 2018.11.011

Meloni, E. G., Venkataraman, A., Donahue, R. J., and Carlezon, W. A. (2016). Bi-directional effects of pituitary adenylate cyclase-activating polypeptide (PACAP) on fear-related behavior and c-Fos expression after fear conditioning in rats. Psychoneuroendocrinology 64, 12-21. doi: 10.1016/j.psyneuen.2015.11. 003

Mercer, K. B., Dias, B., Shafer, D., Maddox, S. A., Mulle, J. G., Hu, P., et al. (2016). Functional evaluation of a PTSD-associated genetic variant: estradiol regulation and ADCYAP1R1. Transl. Psychiatry 6:e978. doi: 10.1038/tp.2016.241

Merriam, L. A., Baran, C. N., Girard, B. M., Hardwick, J. C., May, V., and Parsons, R. L. (2013). Pituitary adenylate cyclase 1 receptor internalization and endosomal signaling mediate the pituitary adenylate cyclase activating polypeptide-induced increase in guinea pig cardiac neuron excitability. J. Neurosci. 33, 4614-4622. doi: 10.1523/jneurosci.4999-12.2013

Miles, O. W., and Maren, S. (2019). Role of the bed nucleus of the Stria terminalis in PTSD: insights from preclinical models. Front. Behav. Neurosci. 13:68.

Miyata, A., Arimura, A., Dahl, R. R., Minamino, N., Uehara, A., Jiang, L., et al. (1989). Isolation of a novel 38 residue-hypothalamic polypeptide which stimulates adenylate cyclase in pituitary cells. Biochem. Biophys. Res. Commun. 164, 567-574. doi: 10.1016/0006-291x(89)91757-9

Miyata, A., Jiang, L., Dahl, R. D., Kitada, C., Kubo, K., Fujino, M., et al. (1990). Isolation of a neuropeptide corresponding to the $\mathrm{N}$-terminal 27 residues of the pituitary adenylate cyclase activating polypeptide with 38 residues (PACAP38). Biochem. Biophys. Res. Commun. 170, 643-648. doi: 10.1016/0006-291x(90) 92140-u

Moench, K. M., and Wellman, C. L. (2017). Differential dendritic remodeling in prelimbic cortex of male and female rats during recovery from chronic stress. Neuroscience 357, 145-159. doi: 10.1016/j.neuroscience.2017.05.049

Muller, A., Joseph, V., Slesinger, P. A., and Kleinfeld, D. (2014). Cell-based reporters reveal in vivo dynamics of dopamine and norepinephrine release in murine cortex. Nat. Methods 11, 1245-1252. doi: 10.1038/nmeth. 3151

Mustafa, T. (2013). Pituitary adenylate cyclase-activating polypeptide (PACAP): a master regulator in central and peripheral stress responses. Adv. Pharmacol. 68, 445-457.

Nakamachi, T., Ohtaki, H., Seki, T., Yofu, S., Kagami, N., Hashimoto, H., et al. (2016). PACAP suppresses dry eye signs by stimulating tear secretion. Nat. Commun. 7:12034.

Nikolaienko, O., Patil, S., Eriksen, M. S., and Bramham, C. R. (2018). Arc protein: a flexible hub for synaptic plasticity and cognition. Semin. Cell Dev. Biol. 77, 33-42. doi: 10.1016/j.semcdb.2017.09.006
Otto, C., Kovalchuk, Y., Wolfer, D. P., Gass, P., Martin, M., Zuschratter, W., et al. (2001a). Impairment of mossy fiber long-term potentiation and associative learning in pituitary adenylate cyclase activating polypeptide type I receptordeficient mice. J. Neurosci. 21, 5520-5527. doi: 10.1523/jneurosci.21-15-05520. 2001

Otto, C., Martin, M., Wolfer, D. P., Lipp, H. P., Maldonado, R., and Schutz, G. (2001b). Altered emotional behavior in PACAP-type-I-receptor-deficient mice. Brain Res. Mol. Brain Res. 92, 78-84. doi: 10.1016/s0169-328x(01)00153-x

Pecoraro, V., Sardone, L. M., Chisari, M., Licata, F., Li Volsi, G., Perciavalle, V., et al. (2017). A subnanomolar concentration of pituitary adenylate cyclaseactivating polypeptide (PACAP) pre-synaptically modulates glutamatergic transmission in the rat hippocampus acting through acetylcholine. Neuroscience 340, 551-562. doi: 10.1016/j.neuroscience.2016.10.061

Piggins, H. D., Stamp, J. A., Burns, J., Rusak, B., and Semba, K. (1996). Distribution of pituitary adenylate cyclase activating polypeptide (PACAP) immunoreactivity in the hypothalamus and extended amygdala of the rat. J. Comp. Neurol. 376, 278-294. doi: 10.1002/(sici)1096-9861(19961209)376: $2<278$ ::aid-cne9>3.0.co;2-0

Quinn, W. G., Sziber, P. P., and Booker, R. (1979). The Drosophila memory mutant amnesiac. Nature 277, 212-214. doi: 10.1038/277212a0

Radley, J. J., Rocher, A. B., Miller, M., Janssen, W. G., Liston, C., Hof, P. R., et al. (2006). Repeated stress induces dendritic spine loss in the rat medial prefrontal cortex. Cereb. Cortex 16, 313-320. doi: 10.1093/cercor/bhi104

Radley, J. J., Sisti, H. M., Hao, J., Rocher, A. B., McCall, T., Hof, P. R., et al. (2004). Chronic behavioral stress induces apical dendritic reorganization in pyramidal neurons of the medial prefrontal cortex. Neuroscience 125, 1-6. doi: 10.1016/j.neuroscience.2004.01.006

Rajbhandari, A. K., Octeau, C. J., Gonzalez, S., Pennington, Z. T., Mohamed, F., Trott, J., et al. (2021). A basomedial amygdala to intercalated cells microcircuit expressing PACAP and its receptor PAC1 regulates contextual fear. J. Neurosci. 41, 3446-3461. doi: 10.1523/jneurosci.2564-20.2021

Ramikie, T., and Ressler, K. (2018). Mechanisms of sex differences in fear and posttraumatic stress disorder. Biol. Psychiatry 83, 876-885. doi: 10.1016/j. biopsych.2017.11.016

Resch, J. M., Maunze, B., Phillips, K. A., and Choi, S. (2014). Inhibition of food intake by PACAP in the hypothalamic ventromedial nuclei is mediated by NMDA receptors. Physiol. Behav. 133, 230-235. doi: 10.1016/j.physbeh.2014. 05.029

Ressler, K. J., Mercer, K. B., Bradley, B., Jovanovic, T., Mahan, A., Kerley, K., et al. (2011). Post-traumatic stress disorder is associated with PACAP and the PAC1 receptor. Nature 470, 492-497.

Ressler, K. J., Paschall, G., Zhou, X. L., and Davis, M. (2002). Regulation of synaptic plasticity genes during consolidation of fear conditioning. J. Neurosci. 22, 7892-7902. doi: 10.1523/jneurosci.22-18-07892.2002

Roberto, M., and Brunelli, M. (2000). PACAP-38 enhances excitatory synaptic transmission in the rat hippocampal CA1 region. Learn. Mem. 7, 303-311. doi: $10.1101 / \mathrm{lm} .34200$

Roberto, M., Scuri, R., and Brunelli, M. (2001). Differential effects of PACAP-38 on synaptic responses in rat hippocampal CA1 region. Learn. Mem. 8, 265-271. doi: 10.1101/lm.40501

Ross, R. A., Hoeppner, S. S., Hellberg, S. N., O’Day, E. B., Rosencrans, P. L., Ressler, K. J., et al. (2020). Circulating PACAP peptide and PAC1R genotype as possible transdiagnostic biomarkers for anxiety disorders in women: a preliminary study. Neuropsychopharmacology 45, 1125-1133. doi: 10.1038/s41386-0200604-4

Rozeske, R. R., Valerio, S., Chaudun, F., and Herry, C. (2015). Prefrontal neuronal circuits of contextual fear conditioning. Genes Brain Behav. 14, 22-36. doi: $10.1111 / \mathrm{gbb} .12181$

Sacchetti, B., Lorenzini, C. A., Baldi, E., Bucherelli, C., Roberto, M., Tassoni, G., et al. (2001). Pituitary adenylate cyclase-activating polypeptide hormone (PACAP) at very low dosages improves memory in the rat. Neurobiol. Learn. Mem. 76, 1-6. doi: 10.1006/nlme.2001.4014

Sauvage, M., Brabet, P., Holsboer, F., Bockaert, J., and Steckler, T. (2000). Mild deficits in mice lacking pituitary adenylate cyclase-activating polypeptide receptor type 1 (PAC1) performing on memory tasks. Brain Res. Mol. Brain Res. 84, 79-89. doi: 10.1016/s0169-328x(00)00219-9

Schmidt, S. D., Myskiw, J. C., Furini, C. R., Schmidt, B. E., Cavalcante, L. E., and Izquierdo, I. (2015). PACAP modulates the consolidation and extinction of the 
contextual fear conditioning through NMDA receptors. Neurobiol. Learn. Mem. 118C, 120-124. doi: 10.1016/j.nlm.2014.11.014

Sehgal, M., Song, C., Ehlers, V. L., and Moyer, J. R. (2013). Learning to learn - intrinsic plasticity as a metaplasticity mechanism for memory formation. Neurobiol. Learn. Mem. 105, 186-199. doi: 10.1016/j.nlm.2013.07.008

Sehgal, M., Zhou, M., Lavi, A., Huang, S., Zhou, Y., and Silva, A. J. (2018). Memory allocation mechanisms underlie memory linking across time. Neurobiol. Learn. Mem. 153, 21-25. doi: 10.1016/j.nlm.2018.02.021

Shen, S., Gehlert, D. R., and Collier, D. A. (2013). PACAP and PAC1 receptor in brain development and behavior. Neuropeptides 47, 421-430. doi: 10.1016/j. npep.2013.10.005

Shioda, S., Shuto, Y., Somogyvari-Vigh, A., Legradi, G., Onda, H., Coy, D. H., et al. (1997). Localization and gene expression of the receptor for pituitary adenylate cyclase-activating polypeptide in the rat brain. Neurosci. Res. 28, 345-354.

Spengler, D., Waeber, C., Pantaloni, C., Holsboer, F., Bockaert, J., Seeburg, P. H., et al. (1993). Differential signal transduction by five splice variants of the PACAP receptor. Nature 365, 170-175. doi: 10.1038/365170a0

Stevens, J. S., Almli, L. M., Fani, N., Gutman, D. A., Bradley, B., Norrholm, S. D., et al. (2014). PACAP receptor gene polymorphism impacts fear responses in the amygdala and hippocampus. Proc. Natl. Acad. Sci. U. S. A. 111, 3158-3163. doi: 10.1073/pnas.1318954111

Takasaki, I., Watanabe, A., Yokai, M., Watanabe, Y., Hayakawa, D., Nagashima, R., et al. (2018). In silico screening identified novel small-molecule antagonists of PAC1 receptor. J. Pharmacol. Exp. Ther. 365, 1-18. doi: 10.1124/jpet.117. 245415

Takuma, K., Maeda, Y., Ago, Y., Ishihama, T., Takemoto, K., Nakagawa, A., et al. (2014). An enriched environment ameliorates memory impairments in PACAPdeficient mice. Behav. Brain Res. 272, 269-278. doi: 10.1016/j.bbr.2014.07. 005

Taxier, L. R., Gross, K. S., and Frick, K. M. (2020). Oestradiol as a neuromodulator of learning and memory. Nat. Rev. Neurosci. 21, 535-550. doi: 10.1038/s41583020-0362-7

Taylor, R. D., Madsen, M. G., Krause, M., Sampedro-Castaneda, M., Stocker, M., and Pedarzani, P. (2014). Pituitary adenylate cyclase-activating polypeptide (PACAP) inhibits the slow afterhyperpolarizing current sIAHP in CA1 pyramidal neurons by activating multiple signaling pathways. Hippocampus 24 , 32-43. doi: 10.1002/hipo.22201

Turrel, O., Goguel, V., and Preat, T. (2018). Amnesiac is required in the adult mushroom body for memory formation. J. Neurosci. 38, 9202-9214. doi: 10. 1523/jneurosci.0876-18.2018

Twining, R. C., Lepak, K., Kirry, A. J., and Gilmartin, M. R. (2020). Ventral hippocampal input to the prelimbic cortex dissociates the context from the cue association in trace fear memory. J. Neurosci. 40, 3217-3230. doi: 10.1523/ jneurosci.1453-19.2020
Uddin, M., Chang, S. C., Zhang, C., Ressler, K., Mercer, K. B., Galea, S., et al. (2013). Adcyap1r1 genotype, posttraumatic stress disorder, and depression among women exposed to childhood maltreatment. Depress. Anxiety 30, 251-258. doi: 10.1002/da.22037

Valentino, R. J., and Bangasser, D. A. (2016). Sex-biased cellular signaling: molecular basis for sex differences in neuropsychiatric diseases. Dialogues Clin. Neurosci. 18, 385-393. doi: 10.31887/dcns.2016.18.4/rvalentino

Varodayan, F. P., Minnig, M. A., Steinman, M. S., Oleata, C. S., Riley, M. W., Sabino, V., et al. (2019). PACAP regulation of central amygdala GABAergic synapses is altered by restraint stress. Neuropharmacology 168:107752. doi: 10.1016/j.neuropharm.2019.107752

Vaudry, D., Falluel-Morel, A., Bourgault, S., Basille, M., Burel, D., Wurtz, O., et al. (2009). Pituitary adenylate cyclase-activating polypeptide and its receptors: 20 years after the discovery. Pharmacol. Rev. 61, 283-357. doi: 10.1124/pr.109. 001370

Wang, M., Yang, Y., Wang, C. J., Gamo, N. J., Jin, L. E., Mazer, J. A., et al. (2013). NMDA receptors subserve persistent neuronal firing during working memory in dorsolateral prefrontal cortex. Neuron 77, 736-749. doi: 10.1016/j.neuron. 2012.12.032

Wellman, C. L. (2001). Dendritic reorganization in pyramidal neurons in medial prefrontal cortex after chronic corticosterone administration. J. Neurobiol. 49, 245-253. doi: 10.1002/neu.1079

Wellman, C. L., Bollinger, J. L., and Moench, K. M. (2020). Effects of stress on the structure and function of the medial prefrontal cortex: insights from animal models. Int. Rev. Neurobiol. 150, 129-153. doi: 10.1016/bs.irn.2019. 11.007

Yaka, R., He, D. Y., Phamluong, K., and Ron, D. (2003). Pituitary adenylate cyclase-activating polypeptide (PACAP(1-38)) enhances N-methyl-D-aspartate receptor function and brain-derived neurotrophic factor expression via RACK1. J. Biol. Chem. 278, 9630-9638. doi: 10.1074/jbc.m209141200

Yiu, A. P., Mercaldo, V., Yan, C., Richards, B., Rashid, A. J., Hsiang, H. L., et al. (2014). Neurons are recruited to a memory trace based on relative neuronal excitability immediately before training. Neuron $83,722-735$. doi: $10.1016 / j$. neuron.2014.07.017

Conflict of Interest: The authors declare that the research was conducted in the absence of any commercial or financial relationships that could be construed as a potential conflict of interest.

Copyright $\odot 2021$ Gilmartin and Ferrara. This is an open-access article distributed under the terms of the Creative Commons Attribution License (CC BY). The use, distribution or reproduction in other forums is permitted, provided the original author(s) and the copyright owner(s) are credited and that the original publication in this journal is cited, in accordance with accepted academic practice. No use, distribution or reproduction is permitted which does not comply with these terms. 